to that found in normal old cells, the later part of this process, if not also the earlier part, being accompanied by autolytic activity. The light-scattering power of the cells rises precipitately at about the time when the percentage of total nucleic acid reaches its peak, and it is thus evident that pronounced physical changes must take place at this point.

The course of events is consistent with the view that the penicillin reacts initially with components involved in nucleotide dissimilation, and that the disturbance of nucleotide balance which follows in the growing cell leads immediately to other complex changes. We have no clear indication how the changes in the nucleotide fraction of the cells affect the glutamic acid accumulation mechanism, if, indeed, there is any direct effect at all. But there seems little doubt that the glutamic acid accumulation mechanism is not affected until after the major changes in the nucleotide fraction have already taken place.

I wish to express my indebtedness to Dr. E. F. Gale for valuable criticism and advice, and to the Medical Research Council for a personal grant.

${ }^{1}$ Cooper, P. D., and Rowley, D., Nature, 168, 480 (1949).

${ }^{2}$ Pratt, R., and Dufrenoy, J., Bact. Rev., 12, 79 (1948).

${ }^{3}$ Smiles, J., Welch, F. V., and Elford, W. J., J. Gen. Microbiol., 2, 220 (1948)

4 Hirsch, J., C.R. Ann. Arch. Soc. Turque Sci. Phys. Nat., Fase. 12 (1943-44).

Chain, E., and Duthie, E. S., Lancet, i, 652 (1945).

- Tulasne, R., and Vendreley, R., Nature, 161, 316 (1948).

' Parker, R. F., and Luse, S., J. Bact., 56, 75 (1948).

Lee, S. W., Foley, E. J., and Epstein, J. A., J. Bact., 48, 393 (1944).

- Gale, E. F., and Taylor, E. S., J. Gen. Microbiol., 1, 314 (1947).

${ }^{10}$ Gale, E. F., and Rodwell, A. W., J. Gen. Microbiol., 3, 127 (1949).

"Krampitz, I. O., and Werkman, C. H., Arch. Biochem., 12, 57 (1947).

${ }^{12}$ Gros, F., and Machboenf, M., Ann. de l'Inst. Past., 74, 368 (1948).

${ }^{13}$ Gale, E. F., Bull. Johns Hopkins Hosp., 83, 171 (1948).

${ }^{14}$ Mitchell, P. (to be published shortly).

${ }^{15}$ Malmgren, B., and Heden, C., Acta Path. et Microbiologica, Scand., 24, 417 (1947).

16. Park, J. T., and Johnson, M. J., J. Biol. Chem., 179, 585 (1949)

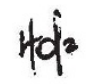

\section{SYMBOLS AND NOMENCLATURE} BY SIR CHARLËTODARWIN, K.B.E. F.R.S.

THE Symbolf Committee of the Royal Society has met intervals during recent years to consider various matters brought to its attention, including of only questions of symbols in physics and chfmotry, but also to some extent of units and of tem hology. These subjects have also been discussed t recent meetings of the International Unions of Chemistry and of Physics, and of the Conference of Weights and Measures (see Nature, March 19 , 1949 , p. 427), and it would scarcely be possible to consider those activities separately. It is thought that readers of Nature may find it useful to have a brief account of these important, though perhaps not very exciting, matters, and the task has been remitted to me. Though I think there is general agreement on the part of the Committee, I must take all responsibility for the views expressed here.

In 1937 there was appointed a committee of the Chemical, Physical and Faraday Societies to prepare an agreed list of symbols covering their joint interests. This list was embodied in a pamphlet which came into widespread use, and it was (with slight modifications) adopted in 1939 by the Royal Society. In 1947 the International Union of Chemistry considered the subject and adopted a system broadly based on the same principles, though making permissible some alternative symbols that have been in wide use in other countries. In 1948 the same list was adopted by the International Union of Physics at its meeting in Amsterdam, again with a few slight changes.

In addition to all the fundamental quantities such as length, force, etc., the list primarily concerns those of joint interest to physics and chemistry, such as thermodynamical and electrical quantities, and it would be out of place to describe the detail here. On the physical side there is, however, one serious omission from the list of symbols in that no attempt has been made to deal with symbols for elasticity. The subject is studied from very different points of view by physicists and by engineers, and it is scarcely surprising that their different demands should have led to different symbols; but even among the physicists and mathematicians there is no consistency. Thus in some notations, the symbol $p_{x y}$ is used for the tensor component of stress-though not always with the same sign-but the corresponding $e_{x y}$ for strain is not a tensor component, but the double of it. Again, among different writers the letter $\sigma$ is used as stress, as dilatation, and as Poisson's ratio. With several authoritative text-books using different long. established notations, there is little hope of ashieving unity; but there might be at least one notationof necessity different from all of them-systematically worked out so that it should be self-consistent. An attempt was made to put one forward at the Amsterdam meeting; but it will certainly be some time before anything more can happen about it.

In this connexion it is curious to note the popularity and unpopularity of various letters for use as symbols for physical quantities. The 26 Roman and 24 Greek letters, both capital and small, seem to provide quite a number of choices; but many of them, like $x$ or $\pi$, are obviously unsuitable, and, indeed, there really is something of a shortage of letters available for any new quantity. But it is scarcely an overstatement that when a writer wants a symbol for a new thing, it is more than probable that he will call it either $\mu$ or $\sigma$, and the shortage is really not so great as all that. Many of these duplications are harmless because they deal with quantities so different that they will never occur together; thus there is no reason why $\mu$ should not stand for coefficient of friction, and coefficient of viscosity (as used by Lamb, though $\eta$ is now the adopted symbol) and for refractive index ( $n$ is now preferred). But it is getting a little dangerous to use it both for magnetic permeability, and for the moment of the mazneton. Some of the uses of $\sigma$ have been mentioned above; but the reader can no doubt think of others. On the other hand, certain letters are practically unused, in particular $\beta$, and it is difficult to see why; it is true that it is often used in the trio $\alpha, \beta, \gamma$, and this might be a reason against its use for other purposes; but for the fact that $\alpha$ and $\gamma$ have a great many other uses.

One of the most important decisions made at the Amsterdam meeting, now finally endorsed by the Conference of Weights and Measures, was to adopt the joule as the unit of heat instead of the calorie. A consequence of this is that the mechanical equivalent of heat disappears from among the list of universal constants, and becomes merely the numerical value of the specific heat of water. The change-over will be certainly troublesome, as are all changes of units; but the definition of the calorie is so confused 
that something had to be done, anyhow. Since the measurement of heat is now usually done electrically, it gives an answer directly in joules, and it is a retrograde step to translate it into calories. The agreement made at Amsterdam was that where a paper gives results in calories, it must state what the conversion factor is that is being used. This course seems scarcely enough in order to get the joule into real use, so that workers should come to think in terms of joules instead of calories. The various scientific societies are being consulted as to the best way of bringing this about. It has to be recognized that it will take time to get used to the unfamiliar unit, and the method that is being explored is that, for example, heats of reaction should always be given in joules, but that the author, if he likes, may add the value in calories afterwards in parenthesis. An essential part of this proceeding must be the prepara. tion of conversion tables, together with a critical review of the matter, since many workers are quite unaware what a vague expression the calorie really is.

Now that the long-established mechanical unit, the joule, is to assume so much greater importance, there is one matter in connexion with it that should be decided, and that is how the word is to be pronounced. There was not long ago a correspondence on the subject in Nature $(152,354,418,479,602 ; 1943)$ which revealed the most surprising disagreement, and more recent inquiries among various people in Manchester confirm these doubts. Some make the great man's name rhyme with 'cool', some with 'cowl', and some even with 'coal'. Thus, Sir Arthur Schuster called him 'Jowl', while Prof. H. B. Dixon, who had a curiosity in such matters, said the name was disyllabic as 'Jo-ull', which would be nearly 'Joal'. On the other hand, Osborne Reynolds in his memoir on him, though he never states how the name is spoken, mentions that it derives from the village of Youlgreave in Derbyshire from which his family came, which would make it 'Jool', and this is the preference of at least some of the surviving family. However all this may be, the word is now to be international, and it is unreasonable to make foreigners suffer from the horrors of English orthography; it therefore seems best that the joule as a unit of heat should rhyme with the word 'cool'-of course, giving the initial 'j' its proper English value.

On the subject of temperature, the Amsterdam conference adopted the sound principle that there should be only one fixed point on the absolute scale instead of the present two, and that this point should be the triple point of water, suitably chosen so as not to alter the existing scale. It will take a little time before this can take effect, because there is still some doubt about the second decimal place of the absolute zero. At the same time, a minor change of nomenclature was agreed-that the name 'centigrade' should no longer be used, but that the scale should be called 'Celsius'. This is the practice already in many countries, and the objection to the word 'centigrade' is that with the present systematization of nomenclature a centigrade ought to mean a hundredth of a grade (the French unit of angular measure, or the German degree), and that the word would be useful for that purpose.

There was a rather strong drive from some quarters at the Amsterdam Conference to replace the C.G.S. by the M.K.S. system of units. This seems to be a subject which runs the danger of being carried by a few enthusiasts against a rather indifferent majority. The Conference took the sensible line of accepting it as admissible; but it very definitely did not recommend that the C.G.S. system should be abandoned by physicists. To some of us this seems important, because the proposal to convert all measures into M.K.S. would put out of date practically every physical table ever printed, changing every number by some troublesome power of ten, and this to very little purpose indeed.

A committee at Amsterdam discussed at some length a proposal for rationalizing the units in radioastivity; the story runs curiously parallel to that of the heat units. The unit used hitherto has been the curie, which was originally defined as the quantity of radon in equilibrium with a gram of radium, but which has gradually come to be used for other sub. stances simply as a measure of the number of disintegrations per second. Some have felt this to be inappropriate, since radium has now the same sort of unimportance in atomic disintegration that water has in the measurement of heat, and it was recently proposed in the United States that a new unit, the rutherford, should be introduced as signifying a million disintegrations a second. The subject involves all the difficulties associated with every proposal for a change of well-established units, and it was finally referred to a joint committee of the Unions of Fhysics and Chemistry which, it is proposed, will supersede the International Commission on Radium Standards. In the meantime, it is proposed as a temporary measure that the 'international curie' should signify $3.6 \times 10^{10}$ disintegrations a second; this number (in place of $3.7 \times 10^{10}$ which has hitherto been used) was adopted as the best rounded number according to recent work in America.

In the nuclear field another small matter of terminology may be noted. The Amsterdam conference attempted to dispose of the curious modern theory that the ancient Greek termination for a fundamental particle was '-tron'. It blessed the word 'meson' as against its rivals, and proposed the adoption of 'positon'.

The Symbols Committee has also given con. sideration to a number of minor points of notation and vocabulary which have arisen from time to time. There is no intention in these of dictating to authors what they should use ; but it was felt that there are a number of matters in which a lead might be given, since some writers may be indifferent and may like guidance. The list is extremely miscellaneous, and many of the suggestions are already in widespread use; some of them have arisen from queries addressed by authors to the Royal Society.

(i) There is the tiresome confusion over the use of lb. or kg. both as measures of mass and of force. To introduce wholly new names for one or other seems impossible at the present time, and to write $\mathrm{kg}$. (mass) is very clumsy. A suggestion made years ago by Prof. Stroud, of Glasgow, seems to provide a reasonable compromise. This is that the force unit should be denoted by a capital letter, so that a mass of $1 \mathrm{lb}$. or $1 \mathrm{~kg}$. when hung on a string exerts a tension of $1 \mathrm{Lb}$. or $1 \mathrm{Kg}$. Again, in a $p V$ diagram as used by the engineer, the ordinate is $\mathrm{Lb} . /$ in. $^{2}$ and the abscissa in. ${ }^{3} / 1 \mathrm{~b}$.

(ii) There is great confusion over the meaning of the 'atmosphere', as there are no less than three possibilities. It would no doubt be scientifically best to use the 'bar' or million dynes per cm.', but this has not been accepted yet in common practice; it is $75.006 \mathrm{~cm}$. of mercury. Then there is what is called the 'technical atmosphere', used by engineers 
in Europe, which is defined as I Kg. $/ \mathrm{cm}^{2}{ }^{2}$; it is $73.555 \mathrm{~cm}$. of mercury for the standard value of gravity. For physics, however, it is agreed that the standard atmosphere should be $76 \mathrm{~cm}$. of mercury at $0^{\circ} \mathrm{C}$. and with $g=980.665 \mathrm{~cm} . / \mathrm{sec}^{2}$. It is proposed that only the last should be accepted as the meaning of 'atmosphere'.

(iii) For work on vibrations it is often convenient to use not the frequency itself, but this quantity multiplied by $2 \pi$. Various names have been proposed for this, but none has gained any very wide acceptance. It is proposed that the most suitable name is 'radian frequency', which brings out the contrast to 'cyclic frequency'.

(iv) There have been various words adopted from the German without translation, and this is a clumsy practice. One was 'Nullpunktsenergie', for which the translation 'zero-point energy' has gradually grown up. This is an ugly word; but it expresses the idea correctly and has already been widely accepted. Another is 'Bremsstrahlung', for which no translation has been found. The German name is bad itself, because the connexion with braking is very remote, and it is an awkward word for an English mouth. It is not easy to think of a name that would give a really significant description of the effect, and it is suggested that 'brake-radiation' would be no worse a misdescription than the German word.

(v) The English practice has hitherto tended to be to use the symbol 'log' for both natural and common logarithms, and when there is danger of confusion to put a subscript $e$ or 10. The practice of denoting the Naperian logarithm by 'In' has much to commend it, and then 'log' will signify only the common logarithm. The subscript would then be mainly used only when the base is neither $e$ nor 10, though it is always possible in case of doubt to retain it for the common logarithm.

(vi) The word 'super-sonic' is sometimes used in two entirely different senses, one for motions faster than the speed of sound, and the other for acoustic vibrations of pitch too high to be audible. It is suggested that it should only be used in the first sense, and that the word 'ultra-sonic'-on the analogy of ultra-violet-should be always used for high. pitched vibrations.

3il6

RESEARCH LABORATORIES OF THE GENERAL ELECTRIC

$\mathrm{T}$ HE Resear haboratories of The General Electric Co., I. than three tho asand guests, including men of science and memb s of other research organisations and industrial cohcerns, at a conversazione held on June 21-23.

These Laboratories, a pioneer industrial research orgation, were founded in 1916 when the late Sir Eifford Paterson (then a principal assistant at the National Physical Laboratory) undertook the formation of a research department for the lamp works of the Company. By 1923, when the Laboratories built at Wembley were formally opened by Lord Robert Cecil and Sir.J. J. Thomson, so many requests for collaboration had been received from other sections of the Company that the original plans had already been extended and the scope of the work considerably increased. The Laboratories now cover a floor area of 200,000 square feet and employ nearly 1,400 personnel, of whom more than 500 are scientific and experimental staff. The scope of the organisation becomes apparent when it is realized that each works and technical department in The General Electric Co. requiring scientific advice is represented by a group of workers in the Laboratories.

There are some thirty-four such units in addition to service groups of analytical chemists, metallurgists, $\mathrm{X}$-ray workers, spectroscopists and others, the services of which are generally available throughout the organisation. The predominant note in the work of all these groups is the giving of scientific service to industry, with two important departures-the fos. tering of fundamental research which may give new knowledge of ultimate use in industry, and the solution of practical production problems associated with the manufacture of new products of the Company.

No event comparable to this conversazione had been held at the Laboratories since their inception, and it was expected that much of the work carried out there might be almost unknown to a large number of the invited guests. In their speeches of welcome, Sir Harry Railing, chairman and joint managing director of the Company, and Mr. O.W. Humphreys, manager of the Research Laboratories, emphasized their desire that the achievements of the Laboratories should be made known to as wide an audience as possible, both among men of science and the lay public. In order to give visiturs a clear picture of the everyday work of the Laboratories, the number of special exhibits was kept to a minimum, and, as far as possible, work was proceeding normally. The fullest freedom of discussion between guests and staff was encouraged in order to achieve the true spirit of a conversazione.

Many of the activities in the field of lighting and illumination were on view. High-pressure mercury. vapour lamps, ranging from 125 watts to $25 \mathrm{~kW}$. rating, were shown and their construction described. Fundamental research is carried out on the properties of the discharge itself, and a very highly loaded flash-discharge lamp is being used to study the behaviour of extremely high current discharges. The latter has application for photographing particle tracks in a Wilson cloud chamber. Recent improvements in the colour-rendering properties and the increased luminous efficiencies of mercury-vapour lamps have extended their applications, both for street lighting and for illuminating motion-picture and television studios. Complementary work on carbon arc lamps also attracted attention.

The qualitative visual assessment of the colour and colour rendering of fluorescent discharge lamps was demonstrated, some of the newest fluorescent materials being shown. The colour appearance of some objects, particularly foodstuffs, is often dependent on the illumination used, and experiments in which their appearance is assessed by a panel of observers were shown in progress. The design and testing of streetlighting lanterns and of fittings for interior lighting were also demonstrated

Samples from each batch of lamps manufactured by the Company are tested for length of life and luminous performance. The racks for the routine testing of tungsten filament, tubular fluorescent, high-pressure mercury vapour, neon and sodium lamps were on view. Photo-electric photometers are used for making accurate routine measurements of 